\title{
EL PATIN DE LAS DAMAS: UN LUGAR OLVIDADO
}

José Manuel Suárez Garmendia

"En Sevilla y en el margen del Guadalquivir que conduce al convento de San Jerónimo, hay, cerca del agua, una especie de remanso que fertiliza un valle en miniatura,formado por el corte natural de la rivera que en aquel lugar es bien alta y forma un rápido declive"..., "un sauce baña sus raíces en la corriente del río hacia el que se inclina como agobiado de un peso invisible y a su alrededor crecen multitud de juncos."

Así veía Gustavo Adolfo Bécquer este paraje del Guadalquivir, aguas arriba del Patín de las Damas y lugar muy frecuentado en sus correrías de juventud, no lejos de la Venta de los Gatos. Paraje, por otra parte, tan presente en sus pensamientos que él añoraba "para dormir el sueño dorado de la inmortalidad".

Fue también en el siglo pasado, en sus décadas centrales, cuando Sevilla sufre un profundo cambio y en mor del progreso y sus adelantos técnicos los sevillanos pierden su convivencia tradicional y su contacto con el río.

Primero fue el establecimientos de la Fábrica de Gas y la Fundición de los Hermanos Portilla en las orillas diáfanas de la que fuera Plaza de Armas y después el establecimiento del Ferrocarril M.Z. A. en este mismo lugar con sus talleres en la Puerta de la Barqueta, lo que hizo desaparecer la relación secular entre el público y el río en toda la margen izquierda.

Desapareció el barrio de los Humeros y todas las defensas que se alzaban desde la Huerta de Colón hasta el Husillo del Taco y con ellas los paseos, el arbolado y los bailes y saraos de las noches de verano del Patín de las Damas. Desde el Puente de Triana, y aguas abajo, la margen estaba ocupada en albergar los almacenes y tinglados del puerto mencante. La gente veía el río, por esta zona, un poco a distancia. Aguas arriba del puente, hasta San Jerónimo, ya no se veía más que en las horas trágicas cuando el Guadalquivir se alzaba sobre sus defensas y hacía acto de presencia en la ciudad. Esta pérdida de contacto con el río ha influido, quizá, en el desinterés hacia él por 
parte de los sevillanos cuyo resultado se nos muestra en el mal estado en que se encuentra.

En este breve trabajo se va a intentar conocer la génesis de este lugar, ya desaparecido, que fue el Pátín de las Damas y sus aledaños que todo el mundo tilda de maravilloso. Pese a que Romero Murube lo incluye en su estudio sobre los jardines sevillanos, este lugar, privilegiado por su situación, nunca fue una zona ajardinada, al menos en el sentido de jardín romántico, aunque para el poeta el propio nombre de Patín de las Damas le traiga recuredos de "música de minué" (1).

Efectivamente, fue el lugar más combatido y más devastado por el Guadalquivir en todas las épocas ya que, con frecuencia inusitada, sus aguas se paseaban por él y sus alrededores como si de su propio lecho se tratara arrasando todo lo que se le oponía y tratando de penetrar en la ciudad siguiendo el mismo camino que antaño le conducía por la Alameda de Hércules, Sierpes y Plaza Nueva hasta el Arenal. Esto nos hace pensar que la vegetación que aquí creció fue la que podía sobrevivir de una inundación hasta la siguiente. Hay que tener en cuenta que las defensas y malecones levantadas en el último cuarto del siglo XVIII, desde los Humeros hasta la Barqueta, no tenían por misión cerrar el paso a las aguas, ello era función de la muralla, sino evitar que el agua se llevara la tierra de las márgenes y llegara a socavar los cimientos de la cerca; lo cual estuvo a punto de conseguir en no pocas ocasiones.

En principio es necesario distinguir lo que fue "Patín de las Damas" y lo que se conocía como "Al sitio del Patín". El Patín propiamente, ya se ha dicho en otro lugar (2), era un espacio elevado de la muralla, el trozo que formaba la esquina de unión entre el paño norte de la cerca que va de la Macarena hasta el río y èl que desde aquí se dirige hasta el sur bordeándolo. Aquí la muralla realiza un quiebro, dándose también la circunstancia de abrirse en este punto la Puerta de la Barqueta con una disposición en eje acodado. Todo ello hacía a este lugar muy vulnerable al río que tenía una particular querencia por la dirección en que inciden sus aguas, ya que es el punto más exterior del meandro que se inicia en San Jerónimo y además porque era su antiguo cauce. Para fortalecer la muralla en este punto se dobló la misma con

(1) Romero Murube, Joaquin. "Los jardines de Sevilla". En curso de conferencias sobre urbanismo y estética sevillana. R. A. B. A. de Santa lsabel de Hungrla. Ano 1955. Sevilla, 1986.

(2) Suárez Garmendia, José Manuel. Arquibectura y urbanismo de Sevilla en el sigho XIX. 
otro paño casi paralelo por el lado interior de la ciudad formando, de esta manera, un espacio trapezoidal que fue rellenado con tierra y cascotes hasta la parte superior de ambos muros organizando así una especie de atalaya a la que se dio acceso mediante una escalera. En varios documentos del siglo XVIII, a los que se hará referencia, se señala como el espacio que existía desde la Puerta de la Barqueta a la esquina que llaman Torre del Gallinote y que en el plano de Matías de Figueroa (Fig. 1) queda perfectamente definido con la letra N.

Por asimilación con este lugar se denominó "Al sitio del Patín de las Damas" el espacio exterior de la muralla que limitaba con el río desde el Husillo Real (junto a la Puerta de San Juan) hasta el Husillo del Taco (104 varas más al norte del Patín de las Damas). En este lugar y con motivo de las obras de defensa que se realizaron en el último cuarto del siglo XVIII, se formó una especie de paseo que estaba bordeado por un pretil donde se establecieron algunos bancos. Fue el primer paseo llamado de las Delicias. Años más tarde este nombre lo tomó el Almaciguero creado por el Asistente Arjona que se ha denominado hasta nuestros días Paseo de las Delicias.

En los terrenos comprendidos al norte del Patín de las Damas se encontraba "un haza de tierra" perteneciente a los Propios de la Ciudad, así como un gran mimbreral junto al río que ocupaban una superficie de "seis y cuarta aranzadas" casi todas ganadas al río después de la obra de 1779 (3). También estaba en este lugar un edificio llamado "el levadero de lanas" perteneciente, al menos desde el siglo XVII, al gremio de los laneros. Asimismo se encontraba en sus cercanías el enorme montón de basura, uno de tantos vaciaderos seculares de la ciudad, que ya consta en el plano de Figueroa de 1730.

Es necesario analizar el origen del Patín para ir reconstruyendo a través de la documentación lo que significó este lugar para Seyilla. Habría que remontarse al año 1383 para , saber por la autoridad del analista Ortiz de Zúñiga, que en este año la ciudad hace una obra de gran importancia y costa junto a la Puerta de la Almenilla para defensa de las avenidas del río Guadalquivir que ya batía sus murallas. Consistían éstas en el terraplenado y relleno de fuerte argamasa entre los muros y el río "creando un espacio grande en que quebrasen las corrientes que aquella parte tiene derecha, en que quedando espacio llano frecuentado de paseos tomó nombre de Patín de las Damas ya en

(3) Archivo Historico Municipal de Sevilla (A. H. M. S.) "Varios Antiguos". Terrenos. Ano 1797. Expediente proponiendo el Señor Síndico Personero para que se le ponga renta al terreno que el río habla aumentado en las terras de propios al Sitio del Patín de las Damas.

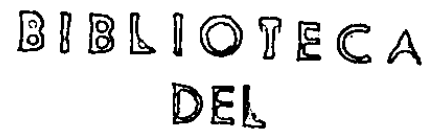


parte arruinado porque el impetuoso torrente ha socavado sus fundamentos..." (4).

De la alusión del texto anterior no ha de interpretarse que el nombre de Patín de las Damas le viniera de esta época (año 1383). En este caso Ortiz de Zúñiga se está refiriendo al momento en que está redactando sus anales, esto es, hacia el último tercio del siglo XVII. En la obra de Collantes de Terán "La Sevilla en la Baja Edad Media" no.consta documento ni referencia alguna donde figure la denominación de Patín de las Damas. Hay que añadir también que en la documentación original que se conserva en el Archivo Municipal sobre las obras realizadas tras la inundación de 1626 tampoco se hace alusión en ningún momento al Patín, nombrándose en cambio a este lugar como Puerta de la Almenilla. Según una última comunicación de A. Collantes de Terán, existe una referencia en el Archivo Municipal de 1585 denominando a este lugar como "Plaza de las Damas" al hacer alusión a unas obras. En 1606 y 1612 lo encuentra nominado como "Patio que llaman de las Damas".

Ha de ser, pues, la fecha clave para esta zona la de 1626, año fatídico para la ciudad conocido para las generaciones posteriores como "el año del diluvio". Todos los historiadores coinciden en señalarle como el más catastrófico a consecuencia de la gran avenida del río. La evaluación que nos hace Ortiz de Zúñiga de los daños supone 4 millones de ducados y no menos de 3.000 casas destruidas. Testigo presencial del acontecimiento fue Rodrigo Caro que nos da cuenta minuciosa del suceso en una carta dirigida a Francisco de Quevedo donde se refleja el pánico de la ciudad en frases tan expresivas como "...viéronse los ratones y los gatos juntos en los tejados y azoteas sin ofenderse unos a otros..." (5).

La cerca de la ciudad quedó resentida en numerosos puntos por la presión del agua pero especialmente en la Puerta de la Almenilla por la dirección que trae el río en este lugar y en prevención de daños futuros "levantose la puerta tanto que su umbral baxo quedó donde estaba el alto de la antigua con que quedó superior, no sólo al río en su ordinario o curso sino en sus mayores crecientes, embebiéndola en un robusto y alto torreón escarpado desde el cual se corrió un través de muralla en parte retirada de la antigua con bastante fondo y fuertes cubos que del todo dexaron segura e incontrastable aquella parte..." (6).

(4) Ortiz de Zúniga, Diego. Anales edesiásticos y seculares de la Muy Noble y Muy Leal Ciudad de Sevilla..., ilustrados y corregidos por D. Antonio Marla Espinosa y Cárcel. Madrid, 1795. Tom. Il. Pág. 219.

(5) Borja Paloma, Francisco. Historia Crítica de las Riadas o Grandes Avenidas del Guadalquivir en Sevilla desde su reconquista hasta nuestros dlas. Año 1878. Tom. I. Pág. 244.

(6) Ortiz de Zühiga, D. Op. Cit. Tom. IV. Pág. 32. 
Hasta aquí el testimonio de Ortiz de Zúñiga que coincide con la documentación del Archivo Municipal. La obra corrió a cargo de Diego Gómez y Juan Nieto (7) ascendiendo su valor a 800.000 r. v. (8) y consta que estaba terminada en el año 1628 , según la lápida que se colocó en la torre cuyo contenido conocemos a través del ya tantas veces citado analista (9).

Esta obra supone el cambio completo de la fisonomía de aquel lugar. Es ahora cuando la Puerta de la Barqueta o Almenilla y la torre de Gallinote, posteriormente llamado Patín de las Damas, toman el semblante que, con las modificaciones que se hacen en sus alrededores al final del siglo XVIII, ha de perdurar hasta su desaparición en los comedios del siglo XIX. No obstante, la impetuosidad del río en las avenidas y la fuerte erosión en todo tiempo hicieron de este lugar el constante punto de atención del Municipio sevillano. También fue el sitio por donde el río se llevó numerosos caudales en obrạs que nunca llegaron a conjurar el problema.

A lo largo de todo el siglo XVII se observa un constante azolvamiento en el lecho del Guadalquivir, según testimonios de los pilotos y prácticos, lo que terminó provocando la ruina del comercio sevillano por vía fluvial. El final de este proceso fue el traslado de la Casa de la Contratación a Cádiz porque los barcos, al aumentar de calado, no podían remontar el río haciéndose frecuentes las faenas de alijar las mercancías al llegar a Coria. Todo esto fue el inicio de una etapa de decadencia de la que Sevilla aún no ha levantado cabeza.

Antes de terminar el siglo XVII el río amenaza de nuevo el Patín de las Damas. En este sentido conocemos su estado por el informe de Don Antonio Bobón, Capitán Ingeniero y Superintendente del Pontón y obras marítimas. Aquí nos da noticias de los calados del río en sus zonas más problemáticas para la navegación y aunque el citado informe es breve y el lugar objeto de nuestro estudio no interesa para la navegación, por estar aguas arriba del puente de barcas, se comenta en el mismo "...que las murallas por la parte de la Puerta de Barqueta, el Patín de las Damas y todo aquel contomo están mui endebles comidos los cimientos, con muchos abujeros y pasadas y se necesita mui prezisamente de acudir al remedio porque están a riesgo de que el río. las rompa y aga mucho daño a esta ciudad por ser estos sitios más inmediatos del río y que en mui poca agua de avenida llege a las mismas murallas..." (10).

(7) A. H. M. S. Secc. 1. Carp. 183. Doc. 209.

(8) Ibid. Escribanías de Cabildo del siglo XVIII. Libro 263.

(9) Ortiz de Züniga, D. Op. Cit. Tom. IV. Pág. 323.

(10) A. H. M. S. Socc. 4.'. Tom. 31. N.' 72. 
Estos daños fueron producidos probablemente en la inundación del año 1684 en la cual "...le faltó solamente pie y medio para que el agua del río rebosara por encima de la muralla del Patín de las Damas..." (11). A ello hay que añadir los daños causados en las siguientes inundaciones de los años 1692 y 1693 que motivaron las importantes obras que se realizaron en el último año citado donde se gastaron "un cuento y quinientos reales de vellón en diferentes estacadas y murallas que se arruinaron mui brevemente..." (12). Tantos fueron los daños que en 1695 "se practicaron en este sitio y con mucho costo estacadas a donde se echaron barcas y cajones grandes cargados de argamasas y piedras de magnitud que se trajeron de las ruinas de Itálica, lugar de Santiponce, y Alcalá del Río y con estos crecidos materiales formaron diferentes ángulos en el rincón del dicho Patín y margen cuyos vestigios aún todavía en aguas bajas hoy se manifiestan desde el desembarcadero de yezo hasta el ángulo o rincón del dicho citio del Patín..." (13).

Este sistema de cimentación en el río es curioso porque se repitió en varias ocasiones con escasa fortuna como en 1718 en que se hundió una urca cargada de piedra y argamasa que importó $150.000 \mathrm{r}$. v. y también porque nos señala a donde fueron a parar muchas de las esperanzas de posteriores arqueólogos. Incluso existe un informe completo y minucioso para realizar estas prácticas proponiendo para estos menesteres los barcos del puente que todos los años se desechaban por su mal estado (14). Pero ni este sistema, ni el destacadas, ni el de dragados a base de pontones fueron suficientes para alejar la madre del río, cada vez más profunda en este punto, que llegó a alcanzar sondas de hasta 14 y 16 varas, probablemente las mayores de todo su cauce.

Entrado ya el siglo XVIII, la preocupación del Cabildo por el estado del río en este y otros lugares es grande pues hay numerosas quejas de los pilotos por los accidentes en los bajos. Pero en el Patín de las Damas el problema era la diversidad del lecho del río, permeable y muy fangoso, que se tragaba

(11) Borja Palomo, F. Op. Cit. Tom. I. Pág. 309.

(12) A. H. M. S. Escribanías de Cabildo del siglo XVIII. Tom. 272. Informe del Marqués de Torreblanca. Ano 1776.

(13) Ibid. "Parecer e informe del rlo Guadalquivir que de orden del Asistente de esta ciudad ha hecho el Mtro. Mayor Segundo del IImo. Cabildo y Reximiento de esta M. N. y M. L. ciudad de Sevilla. Matías José de Figueroa. Año 1745".

(14) Ibid. "Parescer que da Dn. Pedro Juan Laviesca de la Torre, Arquitecto y Maestro Maior del IImo. Cavildo y Reximto. de esta Mui Noble y Mui Leal Ziudad de Sevilla sobire los reparos que convienen para las inundaciones del rlo Guadalquiviry su navegación. Ano 1745". 
literalmente todos los materiales de relleno que le echaban. Las cimentaciones se fundaban sobre estacas clavadas a golpe de martinete hasta que se pensaba haber llegado a un punto lo suficientemente compacto y encima de éstas unidas convenientemente con hierros y cadenas, se labraban los muros. Esta era la técnica que se empleaba en Venecia y que el tiempo se está encargando de demostrar que no es lo suficientemente duradera. Al cabo de los años el pilotaje iba hundiéndose o quedando al descubierto por la acción erosiva de la corriente lo que provocaba el derrumbamiento del muro. La corriente 10 mismo originaba profundidades de 14 varas que, por sedimentación, levantaba en poco trecho una isla como la que existía pocos metros aguas abajo de este lugar.

Este efecto dinámico de la corriente del río inspiró a Matías de Figueroa en 1738 un proyecto ingenieril para transformar las profundidades del río, junto a la muralla del Patín, en orillas o márgenes más suaves y rellenar luego sobre éstas hasta conseguir la altura suficiente para formar un arrecife 0 paseo y alejar de la base de la muralla el peligro del socavón. El sistema no era original pues se venía empleando con éxito en los ríos italianos y franceses. Básicamente consistía en construir unos "dientes". (sic) o muros de contención que, iniciándose en la orilla, avanzan hacia el centro del río con un ángulo determinado de incidencia según el efecto a conseguir siendo la parte superior escalonada o en declive suave hacia la punta. Estos dientes al inferir y aminorar la velocidad del agua producirían en la zona contraria al sentido de la corriente un remanso o zona de quietud suficiente para que se produjese la sedimentación de los materiales en suspensión los cuales acabarían formando el relleno (15). Desde luego, el sistema era económico, eficaz y rápido en conseguir su objetivo, sobre todo en un río como el Guadalquivir en el que habitualmente las islas aparecían y desaparecían en su cauce. La efectividad de este sistema ha quedado demostrada cumplidamente pues es un método que se usa en la actualidad con los mismos fines y en España hay numerosísimos ejemplos, sobre todo en los más rápidos de la vertiente cantábrica.

Por èstos mismos años se suceden varios informes recogidos en el Archivo Municipal. Hay que destacar por su extensión el realizado por el arquitecto municipal Pedro Juan Laviesca de la Torre, fechado en 1740. Para paliar los efectos de las inundaciones es partidario de hacer una gran limpieza en el río a base de pontones, así como realizar en el mismo los cortes de

(15) Vid nota 13 y Sancho Corbacho, Antonio en Arquitectura Barroca Sevillana de los siglos XVII y XVIII. Pág. 149. Aquí se recoge la existencia de varios trabajos realizados por Figueroa en este sentido. 
Merlina y Punta del Borrego, que, además de mejorar la navegación, facilitarian el desagüe del río. Para el Patín de las Damas propone el sistema de hundir barcos o cajones cargados de piedras unidos con lechadas o derretidos de cal para ir formando de esta manera un firme en las márgenes. Con el mismo fin propone el sistema de hacer estacadas que luego se rellenarian de escombros (16).

A pesar de estas propuestas no se acomete ninguna obra en serio, unicamente se realizan obras por valor de "un cuento y 7.000 reales" en 1753 . y 54 por el ingeniero Don Agustín de las Cámaras, con poco éxito al parecer.

La situación del Patín de las Damas y sus alrededores se va agravando con el paso del siglo y las frecuentes avenidas de tal forma que, según los informes emitidos en 1771 por los arquitectos y maestros del Municipio José Martínez Aponte y Pedro y Vicente San Martín, resulta que desde el Husillo Real (desembocaba en la Puerta de San Juan) hasta la Puerta de la Barqueta era tal la estrechez que apenas podía circular entre la muralla y el río un carruaje y llegando al Patín de las Damas sólo podían hacerlo las personas a pie y con grave riesgo. En este mismo informe proponen los citados maestros que debe hacerse una pared o muralla que tenga su arranque en el Husillo Real y que llegue hasta el Husillo del Taco formando a la altura del Patín un espigón que desvie las aguas y que al interior de esta muralla se haga un relleno con los materiales del montículo que exitía en la Macarena.

Este es el primer paso serio de la obra que concluirá ocho años más tarde. Efectivamente, el Cabildo Municipal aprueba el proyecto y los planos pero ha de conseguir licencia del Consejo de Castilla para librar contra los caudales públicos el importe de la obra. Ante esta petición aprovecha el consejo para ordenar que informe sobre las mismas el ingeniero Carlos Witz y Antonio Ulloa (17) dilatándose el comienzo hasta el año 1773. Antonio Ulloa, que no puede venir-a Sevilla personalmente, solicita desde la Isla de León una serie de datos técnicos y el Cabildo sevillano comisiona a Vicente San Martín para que atienda su petición y se ponga a sus órdenes, ya que sobre él habrá de recaer la responsabilidad de la construcción.

Ulloa modifica la disposición del muro sobre el proyecto de San Martín, incluso envía a éste a Cádiz "para que vea el efecto que hace el esfuerzo del

(16) Vid nota 14.

(17) A. H. M. S. "Actas capitulares". Carta, leída por el Conde de la Mejorada en reunión capitular del 29 de julio de 1772. 
agua contra los muros más fuertes para que con este conocimiento proceda en la execución..." (18).

En 1773 y tras la comunicación al Cabildo del Consejo de Castilla permitiendo la utilización de los fondos sobrantes de Propios y Arbitrios, se inician las obras bajo la dirección de Vicente San Martín, siendo el administrador de los fondos el Marqués de Torreblanca.

Estas defensas consistieron básicamente en un muro que se inició en la Puerta de San Juan y que por el margen del río corría paralelo a la muralla hasta el Husillo del Taco. El perfil en planta de este muro es en forma de diente de sierra con lo cual se amortiguaba la fuerza de la corriente. Su alzado se dispone en forma escalonada tal y como había visto San Martín en Cádiz y como son todas las defensas costeras de esta época. Los senos interiores que forman las barrancas de la orilla se rellenaron de escombros hasta la altura superior del muro, con lo.que se consiguió un amplio paseo al borde de la muralla por la orilla del río. En la Puerta de la Barqueta se derribó la Torre del Gallinote, especie de espolón de la muralla del Patín, que avanzaba hasta el río y obstruía el paso, quedando toda la margen diáfana y con el mismo ancho. Enfrentada con la puerta se realizó una rampa y una escalinata en forma de abanico rematada con diferentes adomos que bajaba hasta el río para que la gente pudiera tomar la barca que lo atravesaba en este lugar y bordeando las huertas de la Cartuja dirigirse hasta Santiponce. Este servicio, establecido desde hacía ya mucho tiempo, daba el sobrenombre de Barqueta a la Puerta de la Almenilla o de Vib-Arraguel (19).

Las obras se terminaron en 1779 , siendo asistente de la ciudad Don Francisco Antonio Domezaín, según consta en la lápida que se colocó en 1780 en los muros de la puerta y cuyo contenido conocemos a través de las "adiciones" de Espinosa y Cárcel. Es curioso señalar que en esta lápida, donde abundan los datos de la obra (asistente, arquitecto, fechas, importe de las obras...), no se dice absolutamente nada de su verdadero promotor, que fue Pablo de Olavide, puesto que los expedientes se iniciaron durante su asistencia. Fue la Inquisición la que se encargó de oscurecer la labor de este ilustrado. Esta obra es precisamente, junto con la delineación del barrio de Triana, la única diferencia que existe entre esas dos joyas cartográficas de la

(18) Ibid. Escribanías de cabildo del siglo XVIII. Libro 263. Carta de Don Antonio Ulloa del 15 de enero de 1773.

(19) Los dibujos del proyecto de esta obra se encuentran en la Biblioteca Nacional catalogados en los fondos de A. Barcia con los números 1963 y 1869. 
ciudad, una levantada por orden de Pablo de Olavide en 1771 y la otra dedicada a Pedro López de Lerena en 1788.

La terminación de estas obras solucionó definitivamente el problema, que durante varios siglos tuvo planteado la ciudad, devolviendo la tranquilidad al público que en muchas ocasiones se vio amenazado por el derrumbamiento de sus murallas.

En definitiva, se ganaron unos terrenos al río que sirvieron de antemuro y se aprovecharon para paseos públicos. Asimismo, se solucionó el problema viario que suponía la interrupción de la ronda exterior que antes obligaba a desviar el tráfico hacia el interior de la ciudad.

No pudieron los sevillanos disfrutar por mucho tiempo, apenas ochenta años, de este amplio paseo que les permitía contemplar por un lado el Guadalquivir y por el otro las murallas perfiladas por las espadañas y las torres sevillanas, como diría Murube.

A mediados del siglo XIX, las autoridades municipales para promocionar el comercio y las comunicaciones con el resto de España, solicitaron, en competencia con Cádiz, la instalación del ferrocarril. Por Real Orden, comunicada el 7 de octubre de 1855, la Reina Isabel II aprueba el emplazamiento y distribución de la estación del ferrocarril de Sevilla a Córdoba en los terrenos de la Plaza de Armas, parte del barrio de los Humeros y de los paseos públicos que se extienden en este punto. A partir de este momento ya está echada la suerte del sector occidental de la ciudad. El establecimiento de la estación en su actual emplazamiento hizo cambiar en pocos años la fisonomía de esta parte. Por último, la ordenación y elevación de la calle Torneo por Eduardo García Pérez trajo consigo la desaparición del paño de muralla que unía la Puerta de la Barqueta con la Puerta Real, con inclusión del Patio de las Damas, cuyos terrenos se destinaron a albergar los talleres del ferrocarril.

Qué lejos estaba Bécquer de pensar cuál sería la realidad del paraje que había elegido para dormir el sueño de su inmortalidad "a la orilla del Betis..., en aquel mismo sitio donde iba tantas veces a oír el suave murmullo de sus ondas". 


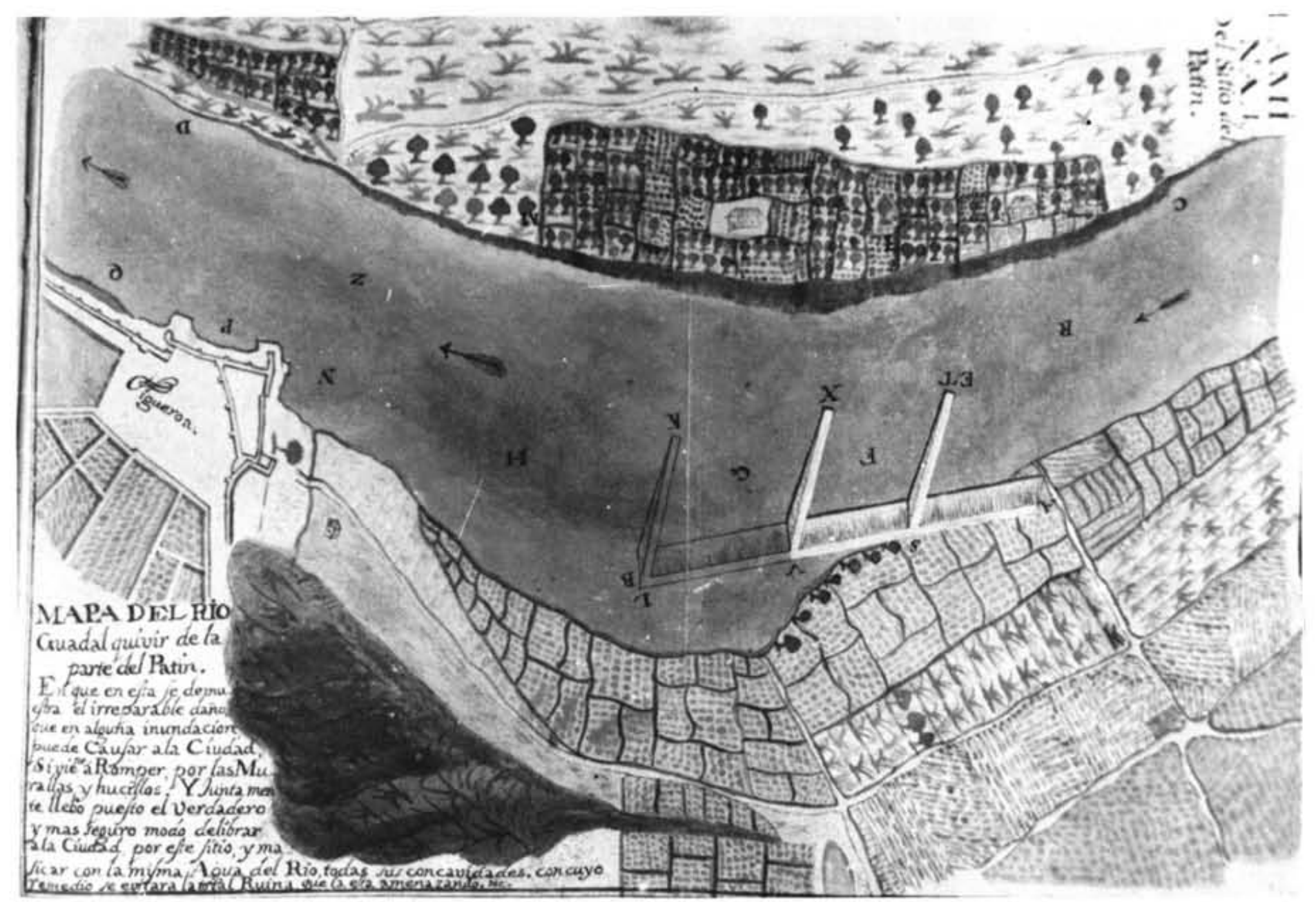

Fig. 1. Proyecto de Matías de Figueroa del año 1738 


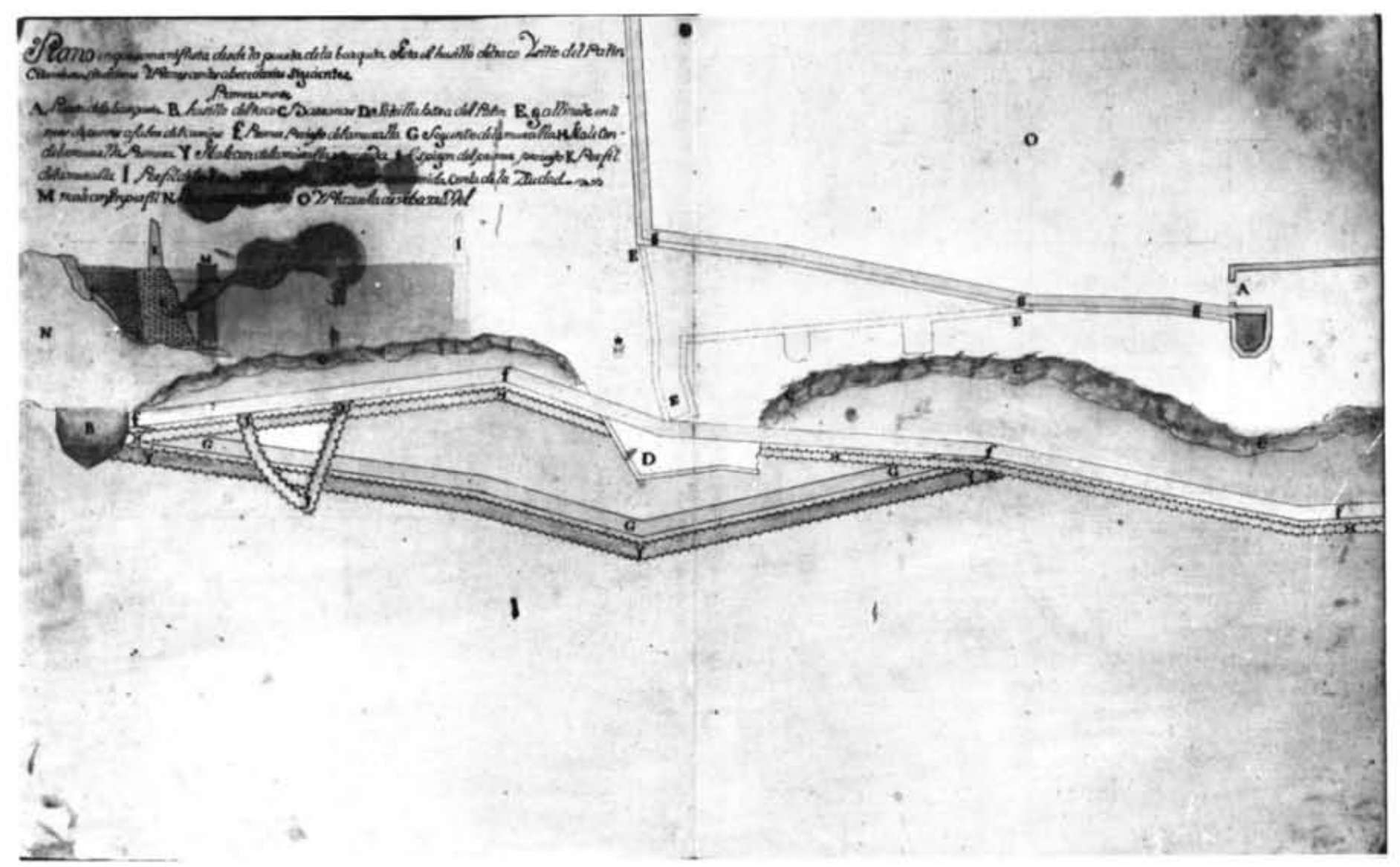

Fig. 2. Plano del lugar "Al Sitio del Patín", entre la Puerta de la Barqueta y el Husillo del Taco, con las reformas proyectadas en 1773. 


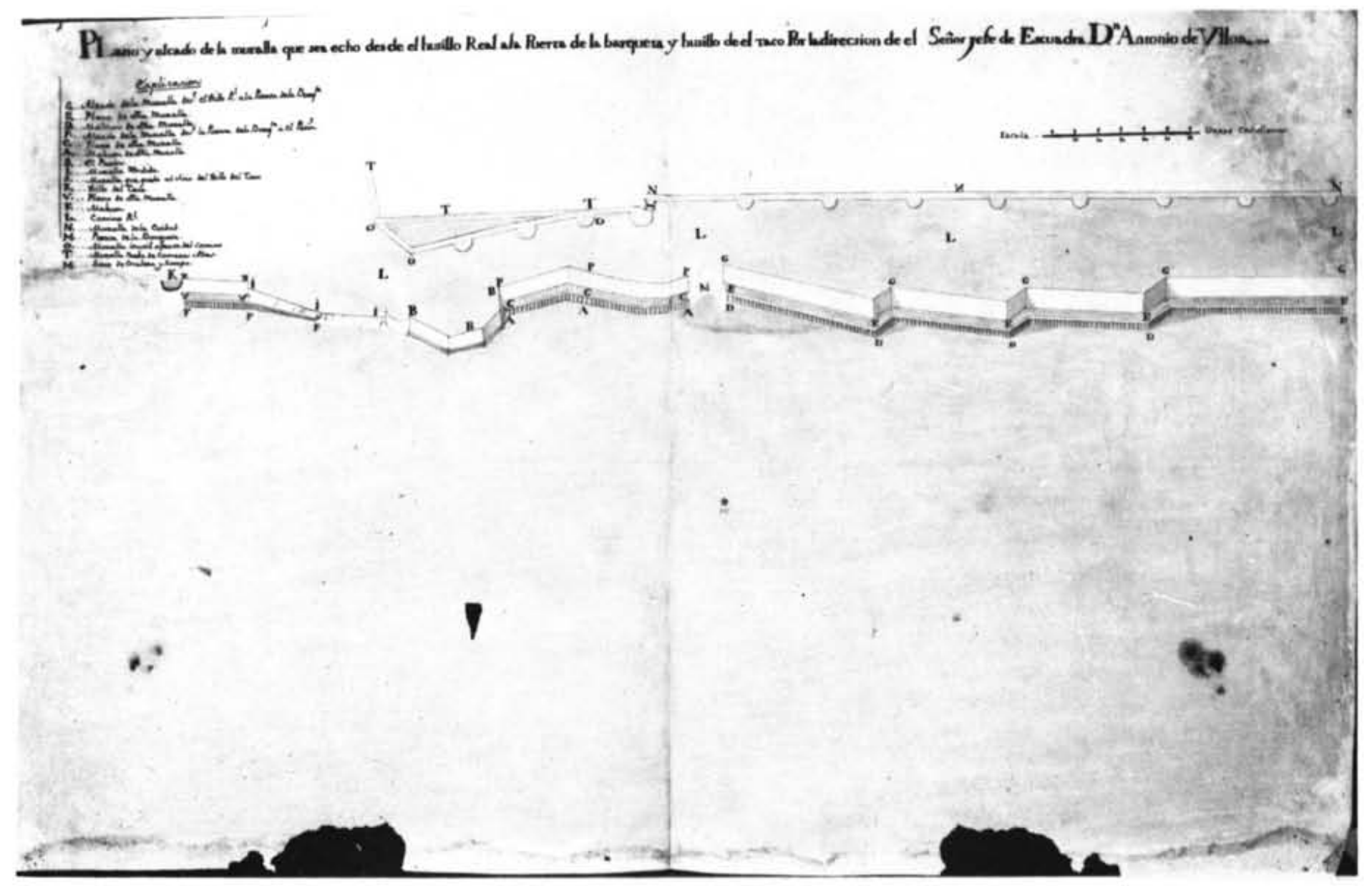

Fig. 3. Plano de las murallas y alzado de la barranca del Patín. Según proyecto de Ulloa. 1773. 


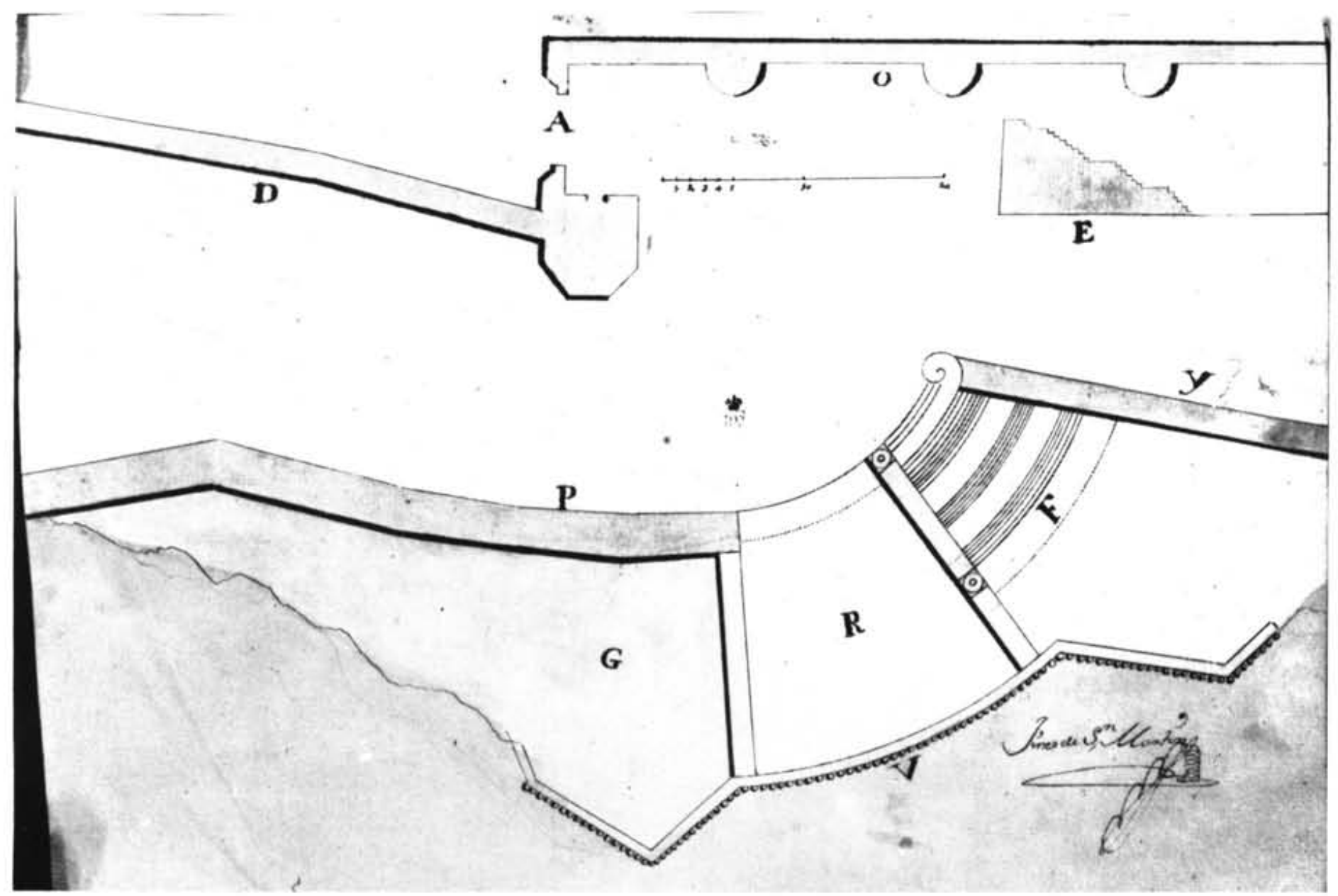

Fig. 4. Plano de la Puerta de la Barqueta y escalera y rampa que bajaba al río para coger la barca. Firmado por Ginés de San Martín. 


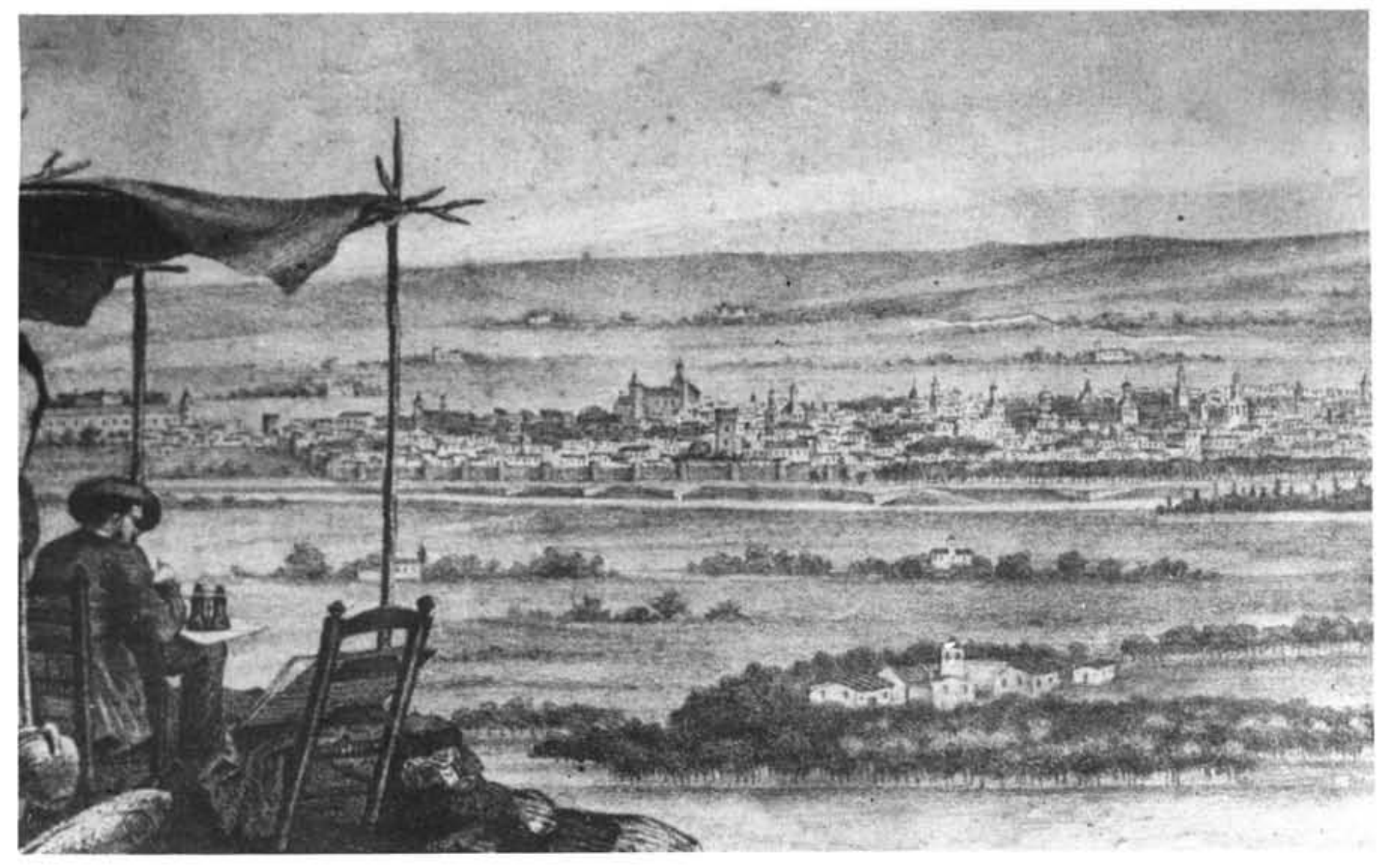

Fig. 5. Vista de las murallas de la calle torneo desde el cerro de Santa Brígida. Hacia 1855. 